\title{
Estimating the Nutritional Value of the Leaves of Moringaoleifera on Poultry
}

\author{
Addai-Mensah Donkor ${ }^{1^{*}}$, Richard Lander Kwame Glover ${ }^{2}$, Daniel Addae ${ }^{1}$, Kawku Appiah Kubi ${ }^{3}$ \\ ${ }^{1}$ Department of Applied Chemistry and Biochemistry, Faculty of Applied Sciences, University for Development Studies, Navrongo, \\ Ghana; ${ }^{2}$ Department of Applied Biology, Faculty of Applied Sciences, University for Development Studies, Navrongo, Ghana. \\ Email: ${ }^{*}$ addaidonkor@aol.com
}

Received July 27 $7^{\text {th }}, 2013$; revised August $27^{\text {th }}, 2013$; accepted September $5^{\text {th }}, 2013$

Copyright (C) 2013 Addai-Mensah Donkor et al. This is an open access article distributed under the Creative Commons Attribution License, which permits unrestricted use, distribution, and reproduction in any medium, provided the original work is properly cited.

\begin{abstract}
In this study, we validated the effect of Moringa oleifera leaves as food supplement on poultry. Proximate neutron activation analysis was used in determining the level of some of the vital nutritional minerals and potential toxic elements in the serum of the birds during the experimental process, including Magnesium, Copper, Vanadium, Chlorine, Aluminum, Manganese, Calcium, Mercury, Cadmium, Arsenic, Sodium and Potassium. Incorporation of Moringa oleifera leaves in maize meal fed to poultry showed profound, statistically significant effect on their weight $(p<0.05)$ as well as intensity in coloration of the beaks and legs, combs and wattles, in contrast to a control (maize-meal only) feeding of broilers $(\mathrm{p}>0.05)$. Moreover, a significant level of the biochemical minerals of serum Calcium $\left(1.17-1.20 \mathrm{mmol} \cdot \mathrm{L}^{-1}\right)$, Sodium $\left(141.6\right.$ - $\left.152.6 \mathrm{mmol} \cdot \mathrm{L}^{-1}\right)$, Potassium $\left(4.1-5.7 \mathrm{mmol} \cdot \mathrm{L}^{-1}\right)$, Chloride $\left(95-110 \mathrm{mmol} \cdot \mathrm{L}^{-1}\right)$, Albumen $(30$ - 55 $\left.\mathrm{mmol} \cdot \mathrm{L}^{-1}\right)$ and Triglyceride $\left(0.3-1.7 \mathrm{mmol} \cdot \mathrm{L}^{-1}\right)$ were observed in broilersfedwith the formulated Moringa oleifera leaves and maize meal as compared to the maize meal only (control). Addition of Maringa oleifera leaves to poultry feed will lead to high output performance in poultry production.
\end{abstract}

Keywords: Moringa oleifera; Neutron Activation; Serum; Poultry; Broilers

\section{Introduction}

Moringa is a tree extending in height from $5-12 \mathrm{~m}$ with an open umbrella-shaped crown, straight trunk between 10 to $30 \mathrm{~cm}$ thick and a corky, whitish bark. The plant, subject to climate has leaflets around $2 \mathrm{~cm}$ in diameter and about $2.5 \mathrm{~cm}$ in length. The tree yields a tuberous tap root which elucidates its acceptance to drought conditions [1]. It is primarily well-thought-out a tree of hot semi-arid regions of annual rainfall ranging from 250 to $1500 \mathrm{~mm}$. Moringa is adjustable to a comprehensive array of environmental conditions from hot to humid and wet conditions. The tree is tolerant to light frosts, but does not subsist as a perennial under freezing conditions [2]. Moringa matures more speedily, reaching higher heights, when found in well-drained soils with sufficient water, but endures sandy soils, heftier clay soils and water deficient conditions. The tree can be established in marginally alkaline soils up to $\mathrm{pH} 9$ as well as acidic soils as low as $\mathrm{pH} 4.5$ [3] and is soundapt for a wide

${ }^{*}$ Corresponding author. range of aggressive environments that would not be appropriate for other fruit, nut and tree crops [4].

Moringa oleifera Lam is one of the 14 species of the family Moringaceae, native to India, Africa, and many parts of the world [5]. Based on [6], the Moringa tree was made known to Africa from India around the twentieth century where it was to be used as a well-being complement. The plant is cited by a number of names such as horseradish tree, drumstick tree, bean oil tree, and a lot more others [7].

Exploration of the diverse parts of the plant is multidisciplinary, comprising but not restricted to nutrition, ethnobotany, medicine, analytical chemistry, phytochemistry and anthropology [8].

The Moringa plant has been expended by humans all over the century in various culinary ways [5]. Virtually all fragments of the plant are used culturally for their nutritional value, ostensible medicinal properties as well as taste and flavor. The leaves of Moringa oleifera can be consumed fresh, boiled, or kept as a dried powder for countless months supposedly without any major damage 
of its nutritional value [9]. Epidemiological studies have specified that Moringa oleifera leaves are a good source of nutrition and display anti-tumor, anti-inflammatory, anti-ulcer, anti-atherosclerotic and anti-convulsant activities [10] (Table 1). The leaves, seeds, flowers, fruit, bark and roots are all used as vegetable [11], and each part is exceptionally harvested and utilized. For example, fresh leaves are picked, shade dried, ground to a powder, and then stored for later use as a food flavoring or additive. Dried or fresh leaves are also used in foods such as soups and porridges, curry gravy and in noodles, rice or wheat [12]. Farmers have included the leaves to animal feed to support a healthy livestock [13-15] while exploiting the manure and vegetable compost for crop growth [16]. Innovative application comprise the use of Moringa powder as a fish food in aquacultural systems [17] and the Moringa leaves as a protein supplement for animals, such as cows. The feeding value of Moringa has been recounted to be analogous to that of soybeans and rapeseed meal [18]. With the leaves being rich in nutrients, pregnant women and lactating mothers use the powdered leaves to enhance their children's nourishment, principally in under developed countries where malnutrition is common $[19,20]$.

Foods having high levels of protein (e.g., soya beans, groundnuts, sunflower seeds) and other feed supplements for poultry production are expensive to purchase while energy foods (e.g., cereal such as maize, sorghum, millets, wheat, rice, maize bran, wheat bran and rice bran by-products) are often plentiful and relatively cheap. Thishas obligated most poultry farmers to move away from this industry leading to low production of poultry meat and eggs and raised the price of poultry products due to high cost of importation. The energy in the diet- necessary for production of poultry meat and eggs and for the maintenance of vital functions and body temperature, are largely in the form of carbohydrates, fats and amino acids which can be found in the leaves of Moringa oleifera. The production of protein in the body tissues entails an adequate supply of about 20 different amino acids, 10 of which cannot be synthesized by poultry, and must therefore be provided in their diets. These essential amino acids are distributed in the leaves of Moringa oleifera all year round [21-23].

The current study sought to validate the potential vital nutritional minerals in the leaves of Moringa oleifera and their effect on the weight and other features of broilers fed with maize meal formulated with Moringa oleifera leaf powder.

\section{Materials and Method}

\subsection{Materials}

Moringa oleifera leaves (MOL) were harvested from an orchard at early flowering stage at Navrongo in the Kassena Nankana District of Upper East Region of Ghana. The plant material was authenticated by Dr. Walter M. Kpikpi, a botanist at the Department of Applied Biology in the Faculty of Applied Sciences of the University for Development Studies, Navrongo Campus.

4-month old broilers were purchased from the Navrongo poultry farm, while maize was obtained from the Navrongo market.

\subsection{Preparation of Moringa oleifera Leaf Powder and Maize-Meal (MOLMM)}

Branches were cut from the Moringa trees, threshed

Table 1. Recommended daily intakes of the various minerals.

\begin{tabular}{|c|c|c|c|c|}
\hline Minerals (nutritional nutrients) & Major function & RDI (Mg) & Deficiency & Toxicity \\
\hline Calcium & $\begin{array}{l}\text { Component of bone and teeth, blood } \\
\text { clothing, nerve transmission, muscle } \\
\text { action }\end{array}$ & $800-1200$ & Osteoporosis & Kidney stone \\
\hline Magnesium & $\begin{array}{l}\text { Bone formation, muscle and } \\
\text { nerve function }\end{array}$ & $280-320$ & $\begin{array}{l}\text { Weakness, muscle } \\
\text { pain }\end{array}$ & Rare \\
\hline Sodium & $\begin{array}{l}\text { Osmotic pressure, nerve } \\
\text { transmission }\end{array}$ & 500 & $\begin{array}{l}\text { Nausea, vomiting, } \\
\text { muscle cramps }\end{array}$ & Possible hypertension \\
\hline Chlorine & $\begin{array}{l}\mathrm{HCl} \text { synthesis, osmotic pressure, } \\
\text { nerve transmission }\end{array}$ & 700 & Rare & Possible hypertension \\
\hline Potassium & $\begin{array}{l}\text { Osmotic pressure, nerve } \\
\text { transmission }\end{array}$ & 2000 & $\begin{array}{l}\text { Heart irregularities, } \\
\text { muscle cramps }\end{array}$ & Slowed heart rate \\
\hline Copper & $\begin{array}{l}\text { Iron metabolism, component } \\
\text { of many enzymes }\end{array}$ & $1.5-3.0$ & Anemia & Rare, vomiting \\
\hline Manganese & Fat synthesis, bone formation & $1.8-2.3$ & Poor growth & $\begin{array}{l}\text { Weakness; nervous system } \\
\text { problems; mental confusion }\end{array}$ \\
\hline Vanadium & $\begin{array}{l}\text { Enzymatic reactions such as metabolism } \\
\text { of carbohydrate and lipids, glucose and } \\
\text { protein }\end{array}$ & $<1.8$ & $\begin{array}{l}\text { Rare. Impairs glucose } \\
\text { metabolism }\end{array}$ & $\begin{array}{l}\text { Damage to both liver and } \\
\text { kidney. Causes gastrointestinal } \\
\text { distress, primary diarrhea }\end{array}$ \\
\hline
\end{tabular}

Source: USDA nutrient database. 
carefully to separate leaves from twigs and weighed. The leaves were spread out on a floor and allowed to air-dry for 4 days under shady and aerated conditions. The dried leaves were ground with mortar and pestle to obtain a leaf powder. The maize was ground at a corn mill to appreciable particle sizes. A $20 \mathrm{~g}$ sample of the maize powder was mixed with $5.0 \mathrm{~g}$ of the Moringa oleifera leaf powder to derive the MOLMM.

\subsection{Management of Experimental Animals (Broilers)}

Five chicken-broilers were allotted to floor pens (2:2:1), with their respective ID numbers of $\mathrm{A} 1$ and $\mathrm{A} 2, \mathrm{~B} 1$ and $\mathrm{B} 2$, and $\mathrm{C} 1$ ) in a randomized complete block design. Sunlight was used as a source of light during the day and fluorescent tubes were used to illuminate the pens at night. The birds were kept under a deep litter management system and "saw dusts" were used as litter materials to cover the floor to serve as absorbents.

\subsection{Experimental Design}

A single diet was formulated in two different phases at 3 -week intervals. The MOLMM was first fed to the broilers in block " $\mathrm{A}$ " for 21 days while those in block " $\mathrm{B}$ " and "C" were given only maize meal (MM). After 21 days, block " $\mathrm{B}$ " broilers were also given same quantities of MOLMM for 21 days while block "A" and "C" broilers were maintained on $\mathrm{MM}$ only. Broilers were made to acclimatize to experimental diet for a period of 7 days prior to data collection. Broilers were provided with ration twice daily at intervals of 7 hours (9:00 am-4:00 $\mathrm{pm}$ ) and water was provided daily. The weight of each broiler was taken from each block at 3-day intervals during the period of study. Observations of color of their beaks and legs, combs and wattles as well as the activeness of the broilers were made.

\subsection{Determination of Nutritional Minerals}

Two milliliter blood samples were collected from the broilers in each block using new sterile needles and syringes through the veins in the wings and placed inside vacutainer test tubes labeled appropriately with corresponding treatment IDs. The blood samples were centrifuged at $3000 \mathrm{rpm}$ for 10 minutes in order to separate the serum. Selected blood chemistry was carried out in the analyzer for some nutritional biochemical minerals at the War Memorial Hospital in Navrongo.

\subsection{Neutron Activation Analysis of Some Vital Nutritional Minerals in Moringa oleifera Leaf}

Proximate neutron activation analysis was carried out on the Moringa oleifera leaf powder, using the Research Reactor-1 at the Ghana Atomic Energy and Commission (GAEC)to determine the presence of nutritional elements such as Magnesium, Copper, Vanadium, Chlorine, Aluminum, Manganese, Calcium, Sodium and Potassium as well as the heavy metals Mercury, Cadmium and Arsenic.

\subsection{Statistical Analysis}

The data were statistically dissected using one-way ANOVA. Results were considered to be statistically significant when $(\mathrm{P}<0.05)$.

\section{Results}

After completion of forty-two (six weeks) treatment the effects of the leaves of Moringa oleifera and maize meal on body weight and levels of some vital nutritional components in the serum of chicken-broilers as well as some nutritional content in leaves were investigated in controlled conditions.

The body weight of broilers fed with MOLMM increased significantly over the 21-day period as compared to those fed on the maize meal only diet (Figures 1 and 2). There was an increase in weight of broiler A1 initially from day 1 up to day 6 , dropped up to day 9 , rose from day 10 up to day 15 , remained steady up to day 19 and rose till day 21 (Figure 1). Broiler A2 showed a similar weight increase pattern except for an initial decrease within the first three days (Figure 1). The weight of broiler B1 kept fluctuating over the initial 21-day period when it was fed with only MM (Figure 2). It increased up to day 5 , dropped by same margin by day 10 , stabilized up to day 15 , rose and declined by same margin up to day 21 before feeding with MOLMM commenced. Its weight then sharply increased within nine days, dipped slightly for a couple of days, shot up for another five days and stabilized up to day 42 . On the other hand, the weight of broiler B2 increased from day one up to three, dropped up to day 6 , remained constant up to day 15 and dropped up to day 21. With the change in diet to MOLMM, its weight increased almost steadily up to day 38 with two slight dips in-between, finally stabilizing till day 42 (Figure 2). Broiler $\mathrm{C} 1$ which was fed with only MM throughout the period of study started with a constant weight for the first 6 days which dropped sharply up to day 9 , stabilized for the next 6 days, increased up to day 18 and decreased again till day 21. Finally, it moved up again from day 24 to 27 and remained at that level till the end of the study (Figure 2).

Effective yellow coloration of the beaks and legs as well as bright coloration of the combs and wattles was observed in broilers fed with MOLMM as compared with only MM-fed broilers. To determine whether or not there 


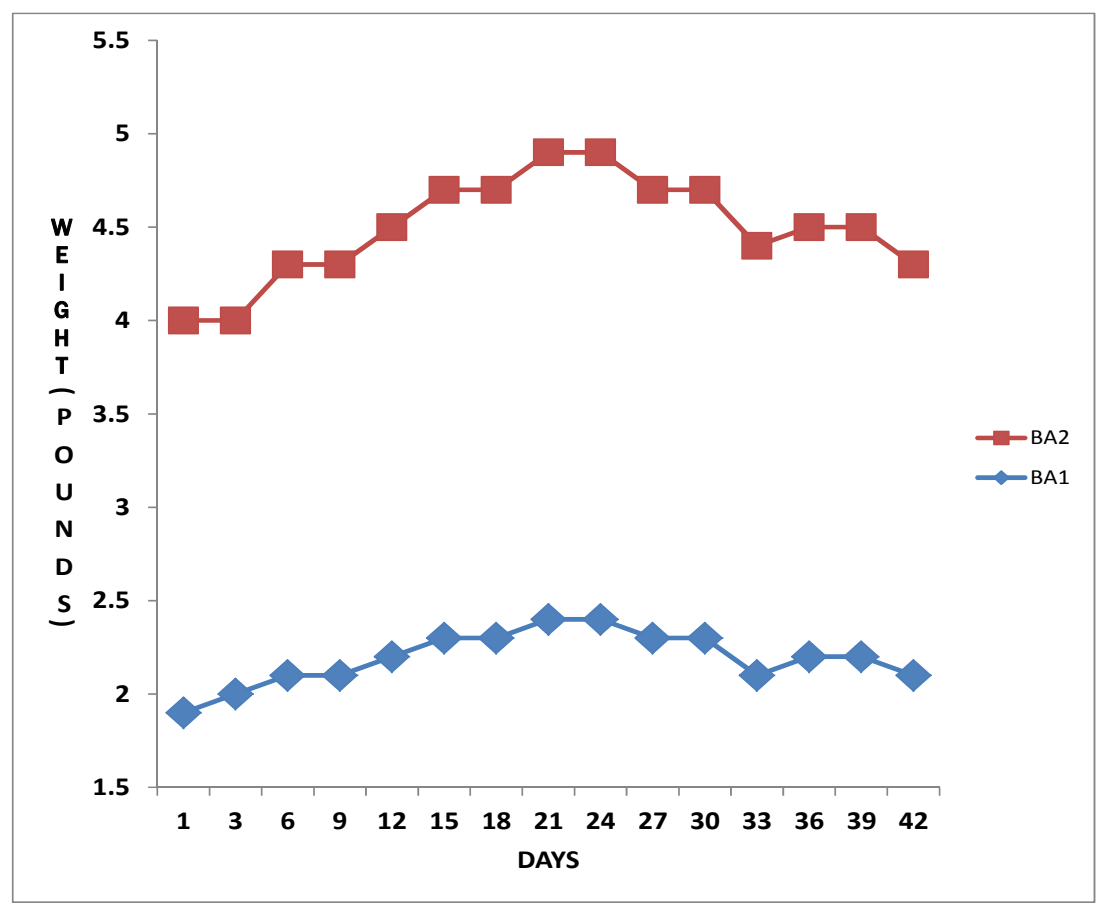

Figure 1. (घ) Variations in weight of broiler A1 fed on Moringa oleifera leaf powder maize meal (MOLMM) for 21 days, and on only maize meal after 21 days until the 42nd day. ( $\diamond)$ Variations in weight of broiler A2 fed on Moringa oleifera leaf powder maize meal (MOLMM) in the first 21 days and on maize meal only after 21 days until the 42nd day.

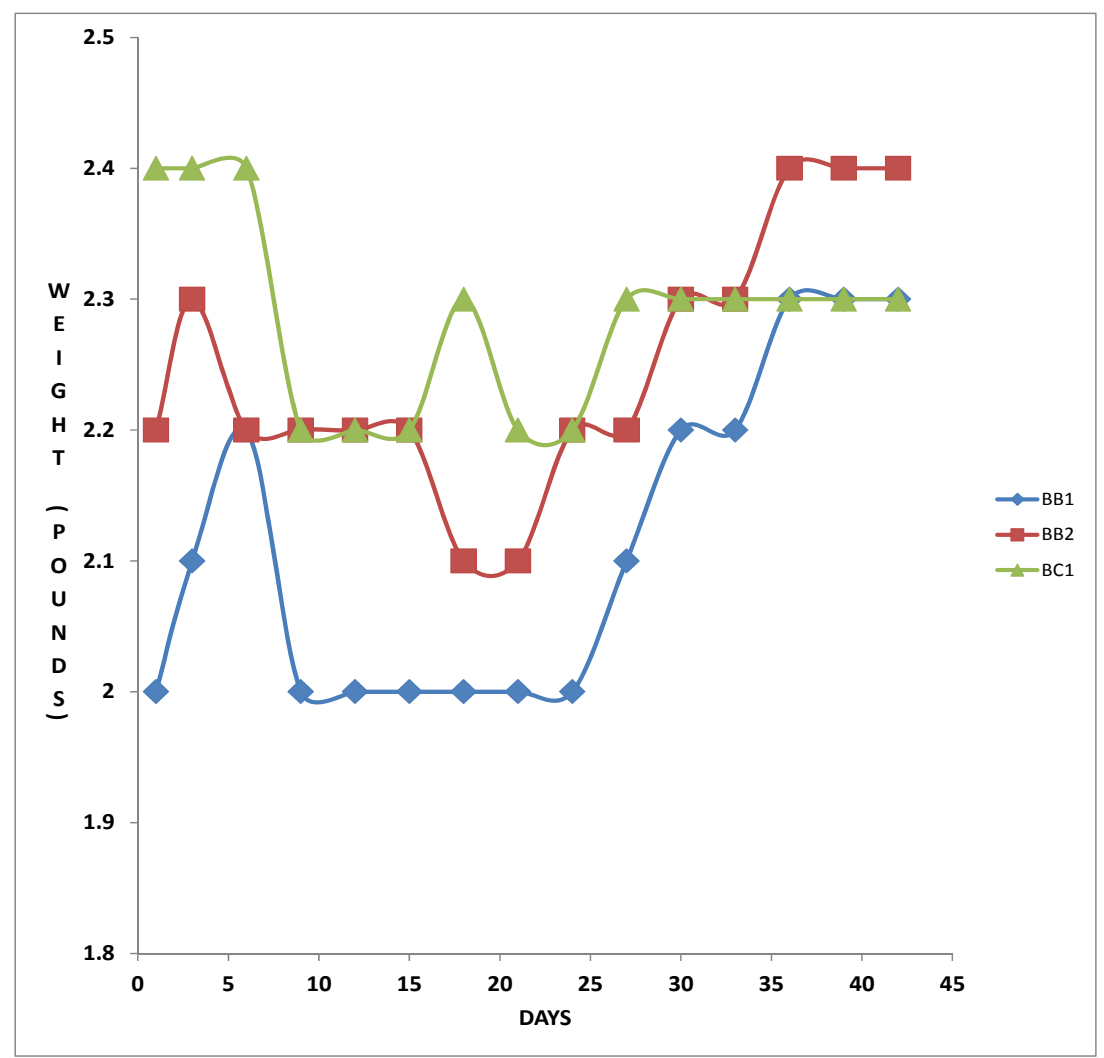

Figure 2. ( $\diamond$ Variations in weight of broiler B1 fed on maize meal only for 21 days and on Moringa oleifera leaf powder maize meal (MOLMM) after 21 days until the 42nd day. ( $($ ) Variations in weight of broiler B2 fed on only maize meal for 21 days and on Moringa oleifera leaf powder maize meal (MOLMM) after 21 days until the 42nd day. ( $\triangle$ ) Variations in weight of broiler $\mathrm{C} 1$ fed on only maize meal for the entire study period. 
was a statistically significant difference achieved by Moringa oleifera leaves meal and maize meal during feeding, A significant effect $(\mathrm{P}<0.05)$ on body weight of MOLMM-fed and insignificant $(\mathrm{P}>0.05)$ on body weight of MM-fed broilers were observed. Higher activity of broilers fed with MOLMM as compared with those on a MM only diet was also observed.

Initial serum samples were taken after 21 days of feeding the broilers due to the difficulty of drawing samples at the earliest infant stage. The total levels of serum Calcium, Sodium, Potassium, Albumen, Triglyceride and Chloride of broilers fed with MOLMM and MM only as well as the reference ranges are shown in (Table 2). Significant increases in total serum levels of Calcium, Sodium, Potassium, Albumen and Chloride were observed for the broilers fed with the MOLMM over the feeding period. There was, however, reduction in serum Triglyceride level of the broilers when fed with the MOLMM. Generally, there was reduction in biochemical serum minerals of broilers fed with MM only (control).

Proximate neutron activation analysis showed that Moringa oleifera leaves abound in vital nutritional minerals namely Magnesium, Copper, Vanadium, Chlorine, Aluminum, Manganese, Calcium, Sodium and Potassium. They were found to be devoid of potential toxic elements such as Mercury, Cadmium, and Arsenic (Table 3).

\section{Discussion}

The present study reveals that the leaves of Moringa oleifera contain most of the major nutritional elements needed for healthy growth as revealed during neutron activation analysis of Moringa oleifera leaf (MOL) powder.

There were no detectable peaks (NDP) for the heavy metals of Mercury, Cadmium and Arsenics which can be toxic to the body when ingested; depicting that MOL is safe for consumption.

There was a significant increase in weight of broilers A1 and A2 when they were fed with MOLMM from day one up to day twenty one and remained stable up to day twenty four. There was then a significant decrease from day twenty four up to day forty two when only MM was used to feed them. The weight remained fairly constant between day twenty one and twenty four when only MM was administered. This could be as a result of the nutritional minerals which were still present in the body. It could be inferred that Moringa oleifera leaves had a significant impact on the weight of the broilers fed with MOLMM through the provision of vital biochemical minerals which might have been absent or inadequate in the normal diet of maize meal (MM) as shown for the control samples. From the present study it was revealed that MOL lowered serum Triglyceride level and increased serum Calcium, Sodium, Potassium, Albumen and Chloride. The latter is justified by the levels of these and other minerals detected in MOL powder after the neutron activation analysis.

Broilers A1 and A2 were initially fed with only maize meal for 21 days before swapping to MOLMM, whilst broilers B1 and B2 were fed with MOLMM for 21 days initially. We therefore speculate that there might be few nutritional minerals in the maize meal which might have also influence significantly the absorption of high nutritional mineral content in the MOL making broilers B1 and B2 had substantial weight gain when feed was supplemented with MOL.

The sample size selected for this particular study were low, as a result the data collected with respect to this study is preliminary and the research still on-going with current analysis comprising a large sample size in our laboratory which would be presented in our next manuscript in preparation.

\section{Conclusions}

Moringa oleifera leaves contain major nutritional minerals needed for healthy growth of animals including poultry. Feeding of poultry with maize meal formulated with Moringa oleifera leaf powder can lead to increase in

Table 2. Analysis of Total Serum Calcium, Sodium, Potassium, Albumen, Triglyceride and Chloride levels of broilers at various stages of the experimental process.

\begin{tabular}{|c|c|c|c|c|c|c|c|c|c|c|c|c|c|c|c|c|}
\hline \multirow{2}{*}{ Mineral } & \multicolumn{5}{|c|}{ First two weeks } & \multicolumn{5}{|c|}{ One month } & \multicolumn{5}{|c|}{ Forty two days } & \multirow{2}{*}{ Standard reference range } \\
\hline & A1 & A2 & B1 & B2 & $\mathrm{C} 1$ & A1 & A2 & B1 & B2 & C1 & A1 & A2 & B1 & B2 & $\mathrm{C} 1$ & \\
\hline Calcium $\left(\mathrm{mmol} \cdot \mathrm{L}^{-1}\right)$ & 1.01 & 1.61 & 1.03 & 1.05 & 1.00 & 1.05 & 2.01 & 1.51 & 1.32 & 1.60 & 1.31 & 2.21 & 1.78 & 2.00 & 1.40 & $1.20-1.73$ \\
\hline Sodium $\left(\mathbf{m m o l} \cdot \mathbf{L}^{-1}\right)$ & 138 & 80.0 & 115 & 128 & 137 & 157 & 161 & 136 & 158 & 149 & 155 & 138 & 152 & 155 & 148 & $141.6-152$ \\
\hline Potasium $\left(\mathbf{m m o l} \cdot \mathbf{L}^{-1}\right)$ & 2.96 & 4.28 & 4.01 & 3.71 & 5.00 & 3.89 & 4.25 & 3.65 & 5.01 & 4.81 & 21.97 & 4.43 & 6.56 & 1.67 & 4.78 & $4.1-5.7$ \\
\hline Albumen $\left(g \cdot L^{-1}\right)$ & 32.2 & 50.3 & 41.7 & 40.7 & 48.7 & 58.6 & 38.5 & 59.8 & 50.8 & 50.0 & 48.6 & 44.7 & 59.7 & 55.8 & 48.9 & $30-55.0$ \\
\hline Triglyceride $\left(\mathbf{m m o l} \cdot \mathrm{L}^{-1}\right)$ & 2.32 & 3.10 & 1.81 & 2.81 & 2.23 & 2.15 & 1.00 & 0.34 & 0.70 & 1.68 & 1.03 & 1.30 & 2.85 & 1.83 & 1.62 & $0.30-1.70$ \\
\hline Chloride $\left(\mathrm{mmol}^{\prime} \mathrm{L}^{-1}\right)$ & 97.0 & 101 & 112 & 96.0 & 91.0 & 117 & 108 & 98.0 & 120 & 99.0 & 108 & 101 & 108 & 104 & 97.0 & $95-110$ \\
\hline
\end{tabular}


Table 3. Nutritional mineral content of dried Moringa oleifera leaf powder (in ppm) and gamma energy released per nutritional mineral (in Kev).

\begin{tabular}{ccc}
\hline Nutrient & Content (ppm) & Gamma energy (Kev) \\
\hline $\mathrm{Mg}$ & 3322.32 & 1014 \\
$\mathrm{Cu}$ & 2.96 & 1039 \\
$\mathrm{~V}$ & 0.449 & 1434 \\
$\mathrm{Cl}$ & 1380.29 & 1642 \\
$\mathrm{Al}$ & 458.22 & 1779 \\
$\mathrm{Mn}$ & 46.07 & 1810 \\
$\mathrm{Ca}$ & 14720 & 3084 \\
$\mathrm{Hg}$ & ${ }^{*} \mathrm{NDP}$ & 77.4 \\
$\mathrm{Cd}$ & ${ }^{*} \mathrm{NDP}$ & 336 \\
$\mathrm{As}$ & ${ }^{*} \mathrm{NDP}$ & 559 \\
$\mathrm{Na}$ & 393.02 & 1369 \\
$\mathrm{~K}$ & 13712 & 1524 \\
\hline
\end{tabular}

*NDP: No Detectable Peaks.

weight, bright coloration of their combs, wattles, beaks and legs as well as general increase in activity of the birds.

Heavy metals like mercury, arsenic and cadmium which are potentially toxic are absent from the leaves of Moringa oleifera, thus making their incorporation into poultry feed safe.

The availability of Moringa oleifera in many rural communities in Ghana makes its use as a supplement for poultry feed an economically viable alternative to expensive commercially produced poultry feeds.

\section{Acknowledgements}

The authors are grateful to the Department of Applied Chemistry \& Biochemistry, University for Development Studies, Navrongo Campus, for providing some of the materials and equipment used in this study; the Department of Applied Biology (Microbiology Laboratory) of the same university for providing the necessary materials for the biological studies; the Ghana Atomic Energy Commission (GAEC), Kwabenya, Accra for the Neutron Activation Analysis of nutritional mineral contents in dried leaf powder of Moringa oleifera and the Navrongo Health Research Centre for the analysis of total serum Calcium, Sodium, Potassium, Albumen, Triglyceride and Chloride levels of broilers at various stages of the research.

\section{REFERENCES}

[1] M. L. Prince, "Maringa Tree," ECHO Technical Note, Educational Concerns for Hunger, 1985.

[2] R. N. Bennett, F. A. Mellon, N. Foidl, J. H. Pratt, M. S. Dupont, L. Perkins and P. A. Kroon, "Profiling Glucosinolates and Phenolics in Vegetative and Reproductive Tissues of the Multi-Purpose Trees Moringa oleifera L. (Horseradish Tree) and Moringa stenopetala L," Journal of Agricultural and Food Chemistry, Vol. 51, 2003, pp. 3546-3553. http://dx.doi.org/10.1021/jf0211480

[3] I. Oduro, W. O. Ellis and O. Deborah, "Nutritional Potential of Two Leafy Vegetables: Moringa oleifera and Ipomoea batatas Leaves," Scientific Research and Essay, Vol. 3, No. 2, 2008, pp. 57-60.

[4] D. J. Kumari, "Hypoglycemic Effect of Moringa oleifera and Azadirachta indica in Type-2 Diabetes," Bioscan, Vol. 5, 2010, pp. 211-214.

[5] S. Iqbal and M. I. Bhanger, "Effect of Season and Production Location on Antioxidant Activity of Moringa oleifera Leaves Grown in Pakistan," Journal of Food Composition and Analysis, Vol. 19, No. 6-7, 2006, pp. 544-551. http://dx.doi.org/10.1016/i.jfca.2005.05.001

[6] D. Mukunzi, J. Nsor-Atindana, X. M. Zhang, A. Gahungu, E. Karangwa, G. Mukamurezi, H. Al-Domi, I. L. Princewill-Ogbonna, P. C. Ogbonna and N. J. Arief, "Comparison of Volatile Profile of Moringa oleifera Leaves from Rwanda and China Using HS-SPM," Pakistan Journal of Nutrition, Vol. 10, No. 7, 2011, pp. 602-608. http://dx.doi.org/10.3923/pjn.2011.602.608

[7] M. S. Dawkins, P. A. Cook, M. J. Whittingham, K. A. Mansell and A. E. Harper, "What Makes Free-Range Broiler Chickens Range? In-Situ Measurement of Habitat Preference," Animal Behaviour, Vol. 66, No. 1, 2003, pp. 342-344. http://dx.doi.org/10.1006/anbe.2003.2172

[8] F. Anwar, S. Latif, M. Ashraf and A. H. Gilani, "Moringa oleifera: A Food Plant with Multiple Medicinal Uses," Phytotherapy Research, Vol. 21, No. 1, 2007, pp. 17-25. http://dx.doi.org/10.1002/ptr.2023

[9] D. Arabshahi and B. A. Ringh, "Adoption of Moringa oleifera to Combat Under-Nutrition Viewed through the Lens of the 'Diffusion of Innovations' Theory," Ecology of Food and Nutrition, Vol. 48, No. 3, 2007, pp. 212-225.

[10] P. Chumark, P. Khunawat, Y. Sanvarinda, S. Phornchirasilp, N. P. Morales, L. Phivthong-Ngam, P. Ratanachamnong, S. Srisawat and K. U. Pongrapeeporn, "The in Vitro and in Vivo Antioxidant Properties, Hypolipidaemic and Antiatherosclerotic Activities of Water Extract of Moringa oleifera Lam. Leaves," Journal of Ethnopharmacology, Vol. 116, No. 3, 2008, pp. 439-446. http://dx.doi.org/10.1016/j.jep.2007.12.010

[11] H. P. S. Makkar and K. Becker, "Nutritional Value and Anti-Nutritional Components of Whole and Ethanol Extracted Moringa oleifera Leaves," Animal Feed Science and Technology, Vol. 63, No. 1, 1996, pp. 211-228. http://dx.doi.org/10.1016/S0377-8401(96)01023-1

[12] R. G. Abilgos and C. V. C. Barba, "Utilization of Malunggay (M. oleifera Lam.) Leaves in Rice (Orya sativa L.) Flat Noodle-Production," Philippine Journal of Sci- 
ence, Vol. 128, 1999, pp. 79-84.

[13] J. Lako, V. C. Trenerry, M. Wahlqvist, N. Wattanapenpaiboon, S. Sotheeswaran and R. Premier, "Phytochemical Flavonols, Carotenoids and the Antioxidant Properties of a Wide Selection of Fijian Fruit, Vegetables and Other Readily Available Foods," Food Chemistry, Vol. 101, No. 4, 2007, pp. 1727-1741. http://dx.doi.org/10.1016/j.foodchem.2006.01.031

[14] S. Ghasi, E. Nwobodo and J. O. Ofili, "Hypocholesterolemic Effects of Crude Extract of Leaf of Moringa oleifera Lam in High-Fat Diet Fed Wistar Rats," Journal of Ethnopharmacology, Vol. 69, No. 1, 2000, pp. 21-25. http://dx.doi.org/10.1016/S0378-8741(99)00106-3

[15] A. Naznin, R. Mamunur and A. Shah, "Comparison of Moringa oleifera Leaves Extract with Atenolol on Serum Triglyceride, Serum Cholesterol, Blood glucose, Heart Weight, Body Weight in Adrenaline Induced Rats," Saudi Journal of Biological Sciences, Vol. 15, No. 2, 2008, pp. 253-258.

[16] L. J. Fuglie, “The Miracle Tree, Moringa oleifera," Natural Nutrition for the Tropics, CWS, Dakar, Senegal, 1999, p. 115.

[17] K. Mehta, R. Balaraman, A. H. Ami, P. A. Bafna and O. D. Gulati, "Effect of Fruits of Moringa oleifera on the Lipid Profile of Normal and Hypercholesterolaemic Rabbits," Journal of Ethnopharmacology, Vol. 86, No. 2-3, 2003, pp. 191-195.

http://dx.doi.org/10.1016/S0378-8741(03)00075-8
[18] C. R. Soliva, M. Kreuzer, N. Foidl, G. Foidl, A. Machmüller and H. D. Hess, "Feeding Value of Whole and Extracted Moringa oleifera Leaves for Ruminants and Their Effects on Ruminal," Animal Feed Science and Technology, Vol. 118, No. 1, 2005, pp. 47-62. http://dx.doi.org/10.1016/j.anifeedsci.2004.10.005

[19] P. Sudha, S. M. Asdaq, S. S. Dhamingi and G. K. Chandrakala, "Immuno-Modulatory Activity of Methanolic Leaf Extract of Moringa oleifera in Animals," Indian Journal of Physiology and Pharmacology, Vol. 54, No. 2, 2010, pp. 133-140.

[20] K. Stephen, M. A. Bangert, J. William, A. Marshall and L. William, "Clinical Biochemistry Metabolic and Clinical Aspects," Elsevier, Philadelphia, 2008.

[21] H. P. S. Makkar and K. Becker, "Plant Toxins and Detoxification Methods to Improve Feed Quality of Tropical Seeds," Asian-Australasian Journal of Animal Sciences, Vol. 12, No. 3, 1999, pp. 467-480.

[22] S. K. Pal, P. K. Mukherjee and B. P. Saha, "Studies on the Anti-Ulcer Activity of Moringa oleifera Leaf Extract on Gastric Ulcer Models in Rats," Phytotherapy Research, Vol. 9, No. 6, 1995, pp. 463-465. http://dx.doi.org/10.1002/ptr.2650090618

[23] P. S. Kumar, D. Mishra, G. Ghosh and G. S. Panda, "Medicinal Uses and Pharmacological Properties of Moringa oleifera," International Journal of Phytomedicine, Vol. 2, 2010, pp. 210-216. 